\title{
International Perspectives of Nurses, Midwives and Allied Health Professionals Clinical Academic Roles: Are We at Tipping Point?
}

\author{
*Debbie Carrick-Sen ${ }^{\mathrm{a}}$, Ann Moore ${ }^{\mathrm{b},}$, Patricia Davidson ${ }^{\mathrm{c}}$, Han Gendong ${ }^{\mathrm{d}}$, and Debra \\ Jackson $^{\mathrm{e}}$ \\ ${ }^{a}$ University of Birmingham, United Kingdom; ${ }^{b}$ University of Brighton, United Kingdom; ${ }^{c}$ School of \\ Nursing, The Johns Hopkins University School of Nursing, Baltimore, Maryland, USA; ${ }^{d}$ Chinese Hospital \\ Management Research Centre, Beijing, China; ${ }^{e}$ University of Technology Sydney, Australia
}

\begin{abstract}
Healthcare research activity improves patient outcomes. Nurses, Midwives and Allied Health Professions (NMAHPs) make an important contribution to clinical research. Within the United Kingdom (UK), there is a 25-year history of increasing healthcare research capacity and capability through clinical academic roles. Medical colleagues were the first to introduce the role in 2005. In 2007, a national policy identified inequalities in access to and success of research training fellowships between medical and nursing healthcare professionals. This was followed by a number of national initiatives, which continue to evolve to the present day. There is evidence that the UK has reached the 'tipping point' to increase NMAHP research capacity and capability through clinical academic roles. Despite these initiatives substantial gaps remain. Outside, the UK, the term 'clinical academic' is not well understood. There is evidence of the presence of senior clinical academic roles, a clinical professor within Australia and the United States, for example, but there is a lack of opportunities and of a formulised research training pathway at a junior level. There is interest and appreciation of the NMAHP research-active clinical academic within the clinical setting in the Nordic countries and China, but the pace of change is slow due to co-existing priorities involving change and innovation. There is a need to develop and agree both national and international definitions that describes the NMAHP research-focused clinical academic role activity.
\end{abstract}

Keywords: clinical academic; international; multi-professional; research capacity and capability building

\section{Introduction}

Research within healthcare is fundamental and important (Department of Health, 2015). Patients involved in research are reporting increased monitoring, more contact with healthcare professionals and increased

*Corresponding Author: Professor Emerita Carrick-Sen, DM. PhD, MSc, PGCE, RGN, RM Professor

Emerita of Nursing and Midwifery, School of Nursing, University of Birmingham, United Kingdom Email: d.carrick-sen@bham.ac.uk

Journal URL: https://publications.coventry.ac.uk/index.php/pblh

Carrick-Sen, D., Moore, A., Davidson, P., Gendong, H., \& Jackson, D. (2019). International perspectives of nurses, midwives and allied health professionals clinical academic roles: Are we at tipping point? International Journal of Practice-based Learning in Health and Social Care, 7(2), 1-15. DOI 10.18552/ijpblhsc.v7i2.648

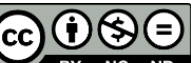

CC ${ }_{\text {BY NC ND }} 2019$ Debbie Carrick-Sen, Ann Moore, Patricia Davidson, Han Gendong, \& Debra Jackson. This Open Access article is distributed under the terms of the Creative Commons Attribution Attribution-NonCommercial No Derivatives 4.0 International License (https://creativecommons.org/licenses/by-nc-nd/4.0/ ), which permits unrestricted non-commercial use, distribution, and reproduction in any medium, provided the original work is properly cited and is unaltered. 
satisfaction (Care Quality Commission, 2018). Research-active organisations report improved clinical outcomes and care quality, and increased research income (Gostin \& Nass, 2009; Hrynkow et al., 2003; Mohammadi et al., 2011; Turner et al., 2017). Encouraging and supporting healthcare professionals to work at maximum professional capability (including research activity) promotes role autonomy, empowerment and satisfaction, and therefore makes an important contribution to the recruitment and retention of high-quality staff (Nedd, 2006). All healthcare professionals including Nurses, Midwives and Allied Health Professionals (NMAHPs) can and do make a valuable contribution to research activity to improve patient outcomes including quality of care and safety (Foster, 2018; Masterson \& Robb, 2016).

\section{What is a Clinical Academic?}

A clinical academic can be defined as a healthcare professional that co-concurrently works within a clinical and academic environment (Department of Health, 2012). Activity of the clinical academic alongside their clinical practice may relate to education and/or research. [A clinical academic's activities side-by-side with their clinical practice may relate to education and/or research]. In the context of this special edition, we have concentrated on the research-focused clinical academic.

\section{What is an NMAHP?}

Globally, NMAHPs are required to be professionally registered. Nursing has the oldest history and identity, yet the role continues to evolve in breadth and scope and has developed into a number of speciality areas (Considine et al., 2006; Gunn, 1969; McConnell et al., 2013; Tiffin, 2012; Wand \& White, 2007). Midwives within the UK have clear identity and scope in terms of role function and autonomy (Nursing \& Midwifery Council, 2018). Outside the UK, the role continues to evolve from maternity nurse to independent practitioner with responsibility and autonomy for low-risk normal pregnancy, birth and postpartum. In comparison, an allied health professional is defined as someone who works in a wide range of professions aligned to medicine. Within the UK, formal professional registration with the Health and Care Professional Council (HCPC) is required. The role has traditionally been associated with extensive role autonomy and specialist practice (World Health Organization, 2019). Within the UK, the HCPC defines Allied Health Professions (AHPs) groupings and include fourteen professional groups, including art therapists, drama therapists, music therapists, chiropodists/podiatrists, dietitians, occupational therapists, operating department practitioners, orthoptists, osteopaths, paramedics, physiotherapists, prosthetists and orthotists, radiographers, speech and language therapists (NHS England, 2019). Within clinical academic role development, the collective is important, since dedicated research funding may be available and the proportion within some of the groups are small; therefore UK initiatives are focused on NMAHPs as a collective rather than on one particular group. In additional, there is more synergy between and within NMAHPs role function than there is between NMAHPs and other medical colleagues (see 'United Kingdom perspective' below for more information). Despite this correlation, within the UK differences are noted between different NMAHP professions in terms of successful highquality research clinical academic fellowships, with Allied Health Professions being more successful than Nurses and Midwives (National Institute for Health Research, 2019a).

\section{What is the difference between a career and training pathway?}

Within healthcare, controversy persists in terms of the difference between a career and a training pathway. A career pathway can be defined as a group of occupations within a career cluster which have shared or common skills, knowledge and/or interests (Minnesota State, 2019), whereas a training pathway can be described as the route or path that one takes to learn the required skills to do a particular job or activity (Collins, n.d.). For the purposes of this Special Issue of the International Journal of Practice-based Learning in Health and Social Care, a career pathway denotes the whole pathway, including, but not withstanding, embedding the role, post objectives and key performance indicators, whereas the training pathway describes the learning and skills required to be a clinical academic.

The core skills required to be a research-focused clinical academic include: developing a good research question and appropriate methodological approaches and methodology, and undertaking the research 
activity to answer the question and dissemination of the findings. However, in addition, leadership skills are key (Carrick-Sen et al., 2015), as is progressive clinical expertise (Department of Health, 2012). Globally, traditional research training is progressive, starting at undergraduate to post-graduate (including Masters) level, through to doctorate and post-doctorate training.

\section{What is the link between research and practice development?}

There is general consensus regarding the term research: a) careful or diligent search; and/or b) studious inquiry or examination, investigation or experimentation to discover and interpret facts, revision of accepted theories or laws in the light of new facts, or practical application of such new or revised theories or laws (Merriam-Webster, n.d.). Conversely, there is no agreed definition of practice development and the term is often used loosely and in differing contexts (Page, 2001). Despite this, over recent years there has been increased interest in and reference to the activity. A useful and contemporary sense has been proposed and is defined as: a systematic approach, perhaps with facilitation that utilises phases of identification and refinement of practice, that includes some or all of the following processes; change, planning, implementation and evaluation (Cioffi et al., 2008). In accepting the proposed practice development definition, there is overlap and close association between the two activities, indeed, it could be proposed that research precedes practice development, and that practice development is the desired consequence to embed evidence into practice.

As there are differences between countries, we detail: a) an understanding of the concept/context; b) the historical context; c) initiatives and challenges; d) a summary together with a consideration of the next steps to be taken, each by country and/or state. The following countries' perspectives are summarised in this article: United Kingdom, Australia, China, the Nordic countries and the United States.

\section{United Kingdom perspective}

\section{Understanding of the concept/context}

Within the UK there is an agreed definition of a NMAHP research-focused clinical academic (Department of Health, 2012) (see above). There are a number of national policy documents that promote and encourage the development of NMAHP clinical academic roles (Coombs, Latter, \& Richardson, 2012; Department of Health, 2012; Finch, 2007; Gullick \& West, 2016; National Institute for Health Research, 2019a; Strickland, 2017). Despite an agreed national definition, confusion still arises occasionally between the role of the nurse/midwife/therapist researcher and the clinical-research nurse/midwife/therapist (Becze, 2010). The latter role embraces responsibility for patient involvement during the delivery of clinical research; by contrast, the nurse/midwife/therapist researcher's role covers development, delivery and dissemination of clinical research (Becze, 2010; Hubbard, 1982; Young et al., 1992).

\section{Historical context}

Within the literature, the first notion of an NMAHP clinical academic role was published in psychology in 1970 (Thelen \& Ewing, 1970) followed by nursing in 1977 (Hicks \& Westphal, 1977). Prior to the establishment of a formal research training programme being available, the majority of senior NMAHP clinical academics within the UK, attributed their success to their tenacity and situational serendipity (Ditzenberger et al., 1995; Eisenberg, 1987; Sculier, 2008; Smith \& Rattray, 2009).

However, since 2007, a number of important national policies and reports have been published that promote and value NMAHP clinical academic roles (Coombs et al., 2012; Edwards et al., 2009; Gullick \& West, 2016). Since 2005, medical colleagues within the UK, have had a well-established research clinical academic training pathway (Walport, 2005). In 2015, the British Medical Association published a report detailing the previous ten years of a formalised medical clinical academic training programme, highlighting successes and identifying existing gaps (British Medical Association, 2015). Despite establishing a very successful training pathway that was fully embedded with a valued and accepted career pathway, gaps remain, including gender and ethnicity inequality, and a lack of flexibility with regard to joining and exiting training (Cregler et al., 1994; Faivre-Finn, 2017; Goldacre et al., 2011). 
In terms of NMAHPs, Professor Joyce Kendre and colleagues on behalf of the Royal College of Nursing (RCN) first developed research competencies aligned to a nurse researcher career framework in 2000. The competencies, although widely cited and valued by individuals, healthcare organisations and national policy makers, were slow to recognise and embed them. In 2007, a critical report (informally known as the Finch report) was published which highlighted major inequalities in terms of research capability and capacity in comparison to medical colleagues (Finch, 2007). The report recommended that dedicated and protected funding be made available to increase nursing and midwifery research capability and capacity. Following the report, a five-year funding programme was established by the Department of Health (DoH) for England and eligibility expanded to include professionals registered with the Health and Care Professional Council (HCPC). Eligibility further expanded in 2014 to include psychologists, healthcare scientists and public health practitioners.

In 2009, Dr Debbie Carrick-Sen, supported by the Department of Health (DoH) now NHS England, founded a group of senior healthcare professionals under the Association of United Kingdom University Hospitals (AUKUH) Chief Nurses Group. Group members included representation from Royal College of Nursing, Royal College of Midwives, and the Council for Allied Health Professions Research (CAHPR), amongst others, and the group was tasked with developing sustainable and embedded NMAHP clinical academic roles. The group produced a number of valuable outputs (see 'Initiatives and challenges') including an interactive guide to assist healthcare organisations to develop and embed clinical academic roles (Carrick-Sen et al., 2016).

In 2012, and within England only, a formal training pathway was established and further funding was provided by Health Education England. The training programme was administered by the National Institute of Health Research (NIHR) and was embedded into the national research training scheme, the NIHR Integrated Clinical Academic (ICA) programme. The scheme initially offered research training at Masters (100 places/year), Doctorate (30 places/year), junior Post Doctorate (five places/year) and senior Post-Doctorate (1-2 places/year) levels. The number of awards offered was capped by quality and available funding.

In 2014, a gap was identified: despite the existence of a dedicated funded research training pathway, some successful awardees reported difficulty in joining, and staying on, that pathway. Therefore, a number of bridging schemes (Hiley et al., 2019), including pre-Masters, Masters to Doctorate and Doctorate to PostDoctorate, were introduced. Following a decade of dedicated national research training funding being available within England, for NMAHPs, inequalities remain. Interesting findings are emerging from national research training schemes, including the NIHR ICA scheme regarding inequalities within and between NMAHP professions. AHPs, especially physiotherapists, have been identified as being the most successful in gaining an award; midwives and nurses have been identified (proportionally) as the least successful. The reason for this is unclear, but research preparedness at professional registration and role autonomy are likely contributors to success.

In 2017, a Clinical Academic Roles Implementation Network (CARIN)

(https://councilofdeans.org.uk/category/policy/research/clinical-academic-roles-implementationnetwork/) was established to guide and support organisations to develop NMAHP clinical academic roles. In February 2018, Health Education England published a Clinical Academic Careers Framework across healthcare professions (Health Eduaction England, 2018). The CARIN network currently has 33 member organisations who are committed to developing and embedding the Clinical Academic role in the clinical setting. More recently, and in response to observed inequalities between NMAHP professional groups, the NIHR launched the Nursing and Midwifery Incubator (National Institute for Health Research, 2019b), the purpose of which is to develop and deliver a number of initiatives that, within five years, will identify, guide and support individual clinical academics and their potential supervisors to develop high-quality funding applications that match the rate of success noted for AHPs.

As the funding is only available within England, different schemes and initiatives exist within the devolved nations of Wales, Scotland and Northern Ireland. Wales has to date focused its effort on the development of research-focused clinical roles, for example, nurse/midwife/therapist consultants, and is now turning its attention to the development of research training opportunities for non-consultant roles. Scotland has a long history of developing and supporting a small number of training opportunities and is 
currently focusing on strategic engagement at the most senior level to influence national (Scottish) policy and the need for a dedicated sustainable research training pathway. Northern Ireland has within recent years focused on the development aspect of research for NMAHP professionals (Condell \& Begley, 2007; McCance et al., 2007). Within England, there is a new drive and interest in the development of NMAHP research capability and capability, led by strong leadership following the development of research champions within AHPs and Nursing and Midwifery known as ‘70@70’ champions.

\section{Initiatives and challenges}

A number of organisations within the UK are successfully building NMAHP research capacity and capability. An important step was to assess baseline and growth. In 2015, the AUKUH group set a target for $1 \%$ of the NMAHP workforce to be a clinical academic by 2030 (Carrick-Sen et al., 2016). The target has been adopted nationally; for some, this was thought to be too ambitious, for others, it was not ambitious enough! The $1 \%$ target compares to an estimated baseline of $0.01 \%$ in 2015 and compares to 5\% within the UK medical profession (Carrick-Sen et al., 2016).

Members of the implementation network have demonstrated movement and growth through the use of a number of different models and foci. For all, the nomination of a senior lead to build research capacity and capability, and engagement with the Trust board has been critical to success. Board engagement has included appreciation and value of NMAHP professionals undertaking and leading research, the development of a NMAHP research strategy, and the identification and agreement of local research priorities and focus. Targeted activity has included focus on NMAHP consultant roles, attainment of Masters' qualification, support and encouragement to undertake doctorate level study, development of service improvement projects using research-based methodology and/or MAGNET focused research, and evidence-based projects.

A small number of research-intensive healthcare organisations have successfully managed to build NMAHP research capacity and capability using a range of initiatives which have successfully impacted all three levels of seniority simultaneously. Here, success was related to having one or more dedicated senior leads for NMAHP research with regular and consistent board support and engagement. In smaller, or less research intensive organisations, success was attributed to a focus on one or two (rather than multiple) initiatives. In essence, within the UK, a mixed model of foci has led to some success.

Despite some measurable success within the UK, a number of challenges remain (Pager et al., 2012). The middle manager remains a substantial barrier that hinders and stifles frontline health professionals (Lionis et al., 2018; Richardson et al., 2019). The reason for this is unclear; possible reasons include worry about staffing levels when releasing healthcare professionals to take up training, a misunderstanding regarding the benefits of having a research-active workforce, and reluctance to support members of the team in acquiring qualifications beyond their own knowledge/ability. Whatever the reason, restricting the development of staff will result in reduced role satisfaction and, potentially, high staffing turnover. There is evidence that senior members of the executive board including Chief Nurses do value and appreciate a research-active workforce, indeed, they recognise and appreciate the link between role satisfaction and retention of high-quality staff. Furthermore, there has been a number of successful campaigns, for example, the making space for research campaign (Tinker, 2019), that has increased awareness in frontline staff regarding the options and opportunities in research roles. It would appear, therefore, that there is a need for initiatives to engage and encourage middle managers to promote, enthuse and support healthcare professionals to be research-trained and research-active.

Within the UK healthcare education system, there is an increasing readiness to introduce research training to students at a much earlier point. A number of Higher Educational Institutes (HEI's) now introduce the fundamentals of research training at pre-graduate level. Over the last two decades, there has been a change to the NMAHP qualification leading to registration, with a move towards the graduate training of registered nurses. Conversely, Midwives and Allied Health Professionals have had a longer history of graduate training and therefore are more likely to have received research training at an earlier point in their career. It is possible therefore, that Midwives and AHP's in the main have increased confidence in undertaking and leading research in comparison to nurses. 
A further challenge relates to embedding the role. It is relatively straightforward to develop a verifiable research training pathway. Each stage requires learning objectives and appropriate teaching/learning and assessment to demonstrate/ evidence meeting each objective. In terms of the clinical academic training pathway, it has been proposed that training objectives be divided into early/junior, mid and late/senior career (Carrick-Sen et al., 2016), the expectation being that research knowledge and ability, clinical expertise and leadership skills are integral and can progress on a continuum (somewhat aligned to the notion of novice to expert). However, developing a career pathway is more complex and subjective.

Within healthcare, developing a new career pathway requires role clarity, objectives and agreed transition points that are embedded into national and local policy, as well as organisation awareness, and acceptance and value of the role itself. Whether research is an essential requirement to an NMAHP role, or indeed whether it should be, is frequently debated. Within the UK, the NMC/HCPC codes of practice confirms this requirement, by stating that it is the registrant's responsibility to ensure that they are aware of current evidence and apply evidence-based practice (Nursing \& Midwifery Council, 2018). However, to meet the code, a registrant is required to have the knowledge and skills to understand and interpret evidence, not necessarily to undertake research activity. If it is accepted that all registrants should undertake research activity, then further debate will be needed regarding required level and experience. The notion relates to the ongoing discussion of whether NMAHP roles are based on an art and/or a science.

\section{Summary/next steps}

In summary, the United Kingdom, particularly England, has made substantial progress towards developing and embedding NMAHP clinical academic roles. To assess progress and success, it is important that an objective is measurable. It is easy to measure attainment of research training. This can be achieved by counting the number of trainees at each level and the number of successful awards. However, measurement and assessment of the success of embedding the role is more complex and difficult. There is a need to have a mutual understanding and agreement of what success is in this context. Could we measure the number of NMAHPs engaged in research activity? If so, we would need to be clear regarding the definition of research activity. Should/could we measure the number of NMAHPs with a post-graduate qualification that incorporated a research training element? Should/could we count the number of NMAHPs that have a $\mathrm{PhD}$ and work in the clinical setting, as has been done in Nordic countries? Finally, there is a need to have a national and preferably international agreed definition of what success is.

\section{Australian perspective}

Australia has a two-decade history of developing and supporting research-focused clinical academic roles. The title of a clinical academic is recognised, especially in terms of the Clinical Professor. The role was first noted in the literature in 2000 (Campbell \& Taylor, 2000). A formal national research training pathway is not recognised, nor has one been developed. However, the idea of formal joint appointments, especially at a senior level, are available and are financially supported by a healthcare provider organisation and higher education institute. In recent years, there has been some criticism regarding expected key performance indicators of clinical professors (Eley, 2018; Friesen et al., 2014).

To date the focus has been on activities related to service improvement/evaluation-related projects. It is of interest to note that such projects are particularly valued and requested by the healthcare provider organisation. Globally, there are inequalities of post joint-funder expectations. In summary Australia, continues to develop and review a number of senior clinical professor appointments, and the greater part of their activity continues to focus on practice development/service improvement and/or evaluation projects. No clinical academic formal training pathway is in place and there is a lack of available clinical academic joint appointments at early career. 


\section{China perspective}

Within China, a developing country, specialist NMAHP roles are emerging. In particular, China's Thirdgrade class-A hospitals in Beijing, Shanghai and other first-tier cities have begun to explore and practise. However, it is inseparable from the scientific research support of higher education institutions and research institutes. For example, the four-in-one research nurse position management mode proposed by the Henan Provincial People's Hospital, which provides the "selection-cultivation-appointmentassessment evaluation", provides a clear pathway for the career development of highly educated nurses (Liu et al., 2018). However, the definition of clinical academic roles has not yet been formed from the national policy level. AHP roles do exist and are valued, but they are clinically-focused within small private organisations. NMAHP research-active post-holders are currently employed by higher education institutes and focus on three research activities: developing high-level grant applications, the collection of large data sets, and publications.

Taking nurses as an example, most nurses involved in research in Chinese hospitals are research nurses, not nursing researchers. Their role is complementary, and there are still big gaps in terms of the NMAHP clinical academic role. The following factors will inevitably affect the professional development of NMAHP's clinical academic role: insufficient investment in research activities for nurses/midwives; lack of specific policies to support nursing/midwifery for research activities; lack of systematic training for general nurses; low educational background and qualifications of nurses/midwives; and allocation of human resources difficulties.

In 2017, Shang Shaomei and others from Peking University School of Nursing investigated the current situation of nurses' research capacity and training needs in tertiary hospitals in 22 provinces and cities in China (Shang et al., 2018). The results showed that $1,130(4.1 \%)$ of the nurses participating in the survey had hosted or were conducting research projects, 2,147 (7.9\%) had participated in or were participating in research projects, and 1,463 (5.4\%) had published papers. Five hundred and seven $(2.0 \%)$ had obtained patents; the total self-assessment of scientific research ability was 25.0 (SD 12.5-37.5); the total demand for scientific research training is 53.1 (SD 37.5-75.0). As a result, insufficient research capacity has become one of the main factors hindering the development of scientific research by Chinese clinical nurses. Use of English, and statistics, were identified as the key obstacles to improving Chinese nurse scientific research level.

At present, more and more highly educated nursing talents are involved in clinical research activities. The concept of evidence-based medicine is applied increasingly to clinical nursing and clinical academic activities. With the development of Chinese nursing professional education, such as nursing theory exploration, nursing professional innovation, inter-professional cooperation, basic research in nursing, etc., this trend provides more platforms for NMAHP talents. Combining theoretical research with practice will bring more change and innovation to clinical practice.

In summary, the clinical academic role of NMAHPs needs to be defined, and the corresponding management systems, including the defining of job responsibilities, competency standards, performance evaluation, and qualification certification, need to be established. With NMAHP career planning and development of pathways, embedded NMAHP clinical academic roles in medical institutions should become inevitable. People-oriented activation of empowerment is key.

\section{Nordic countries perspective}

The Nordic countries make up a region in Northern Europe and the North Atlantic which consists of Denmark, Finland, Iceland, Norway and Sweden and their associated territories, the Faroe Islands, Greenland, Svalbard and Åland. Within the Nordic countries research-active NMAHP clinicians are appreciated and valued. To date, focus has been on the identification and value of the PhD-trained professional within the clinical setting (Nielsen et al., 2015; Sørensen et al., 2019). Despite having a value there is no standardised research training or formal identification as a NMAHP clinical academic. However, there is interest in developing a formalised training pathway for aspiring clinical academics. 
Meanwhile they plan to build on roles that have an existing or potential core research component, eg: nurse/midwife/AHP consultant and/or nurse/midwife/AHP specialist.

\section{USA perspective}

The United States has a good understanding of the value and identity of the clinical academic (Adams et al., 2018; Bowman \& Gardner, 2001; Havens et al., 2002; Huenneke et al., 2017; Peloquin \& Abreu, 1996; Squires et al., 2017); in line with other developed countries, senior posts such as a clinical professor are recognised and available. The focus has predominantly been on medical and nursing roles, although a small number of senior midwifery clinical academic roles are noted, in additional to a scattering of senior AHP clinical academic roles (Squires, 2019). There is evidence of a research training pathway being available. Within the USA, a large number of hospitals aspire to the attainment of MAGNET accreditation (Jamerson et al., 2011; Leao et al., 2013). Within the MAGNET framework, research and provision of evidence-based care is fundamental to attain MAGNET accreditation status. Therefore, in the majority of MAGNET hospitals, research activity is embedded into every-day practice through clinical governance structures. There is substantial evidence of improved nursing care and patient outcomes within MAGNET accredited hospitals. The contribution of research to the improved outcomes is not yet ascertained, as factors are likely to be complex and multifaceted.

\section{Definition and limitations}

On reviewing the literature and contacting a number of colleagues within other countries, including New Zealand, Spain, Canada and some African states, the term clinical academic was not widely understood nor recognised. However, within the literature there is evidence of a number of developments within developing countries (Cannaby et al., 2017; Fatima et al., 2019; Gureje et al., 2019; Macpherson, 2019; Masood et al., 2017; Mormina, 2019; Nair et al., 2016; Pilowsky et al., 2016). There is a dearth of evidence within many countries pertaining to the notion and mechanism of research capacity building within medical and NMAHP professions (Matus et al., 2018; Ryan et al., 2019; $\underline{\text { Sabey et al., 2019; Viney }}$ et al., 2019). Another interesting analogy is in the use of the term nurse scientist and/or nursing science (Albert et al., 2019; Jeffs et al., 2013). Certainly, within Europe (but excluding the United Kingdom), NMAHP research activity is frequently described utilising the term nurse scientist or nursing science. There is a need for both nationally and internationally agreed definitions of NMAHP research activity. This is important and would enable one to describe and share initiatives related to the development and sustainability of research training pathways and roles. The development of the NMAHP clinical academic role is one mechanism to increase research capacity and capability within healthcare. As there is clear identity and value of the medical research-focused clinical academic, it is proposed that consideration should be given to the continuing development of NMAHP clinical academic roles.

\section{Conclusion}

Research-active healthcare provider organisations have improved patient outcomes. NMAHPs make an important contribution to this agenda. There is much variation between countries in the understanding and development of NMAHP research-focused clinical academic roles. The UK continue to pursue and develop NMAHP clinical academic roles. Despite a number of successful initiatives being in place, gaps remain, although it would be acceptable to suggest that within the UK, we have reached the 'tipping point' of sustained progress. Other countries currently use different definitions to describe NMAHP research activity including 'nursing' science. It would be helpful if nationally and internationally agreed definitions were developed to describe the NMAHP researcher and the research training pathway. Embedding and valuing the research-focused clinical academic role in an authentic and meaningful way is critical to further develop and sustain NMAHP-led research activity within the healthcare provider clinical setting. 


\section{ORCID}

Debbie Carrick-Sen:

https://orcid.org/0000-0002-2903-8649

Ann Moore:

https://orcid.org/0000-0001-7627-3492

\section{References}

Adams, J., Kawchuk, G., Breen, A., De Carvalho, D., Eklund, A., Fernandez, M., Funabashi, M., Holmes, M. M., Johansson, M. S., de Luca, K., Moore, C., Pagé, I., Pohlman, K. A., Swain, M. S., Wong, A. Y. L., \& Hartvigsen, J. (2018). Leadership and capacity building in international chiropractic research: Introducing the chiropractic academy for research leadership (CARL). Chiropractic \& Manual Therapies, 26, 5. https://doi.org/10.1186/s12998-018-0173-3

Albert, N. M., Chipps, E., Falkenberg Olson, A. C., Hand, L. L., Harmon, M., Heitschmidt, M. G., Klein, C., Lefaiver, C., \& Wood, T. (2019). Fostering academic-clinical research partnerships. Journal of Nursing Administration, 49(5), 234-241. https://doi.org/10.1097/NNA.0000000000000744

Becze, E. (2010). Defining the role of the clinical research nurse. ONS Connect, 25(5), 12-13.

British Medical Association. (2015) Walport 10th Anniversary Symposium Goodenough College. www.bma.org.uk/-/media/files/pdfs/developing\%20your\%20career/finaWALPORTsymposium-report.pdf

Bowman, C. C., \& Gardner, D. (2001). Building health services research capacity in nursing: Views from members of nursing's leadership. Nursing Outlook, 49(4), 187-192. https://doi.org/10.1067/mno.2001.116334

Campbell, M., \& Taylor, J. R. (2000). Academic and clinical collaboration. Contemporary Nurse, 9(3-4), 211-219. https://doi.org/10.5172/conu.2000.9.3-4.211

Cannaby, A. M., Gkantaras, I., Finn, A., Foreman, B., Butler, G., Topping, A., \& Gray, R. (2017). Implementing a nursing systems framework in a developing country. International Nursing Review, 64(3), 345-352. https://doi.org/10.1111/inr.12380

Care Quality Commission. (2018). The state of health care and adult social care in England 2017/18. https://www.cqc.org.uk/sites/default/files/20171011_stateofcare1718_report.pdf

Carrick-Sen, D., Baillie, L., Deaton, C., Lowes, L., McCabe, C., Norton, C., Tod, A., \& Robb, E. (2015). Improving nursing research activity: The importance of leadership. British Journal of Nursing, 24(14), 751. https://doi.org/10.12968/bjon.2015.24.14.751

Carrick-Sen, D., Richardson, A., Moore, A., \& Dolan, S. (2016). Transforming healthcare through clinical academic roles in nursing, midwifery and allied health professions: A practical resource for healthcare provider organisations. https://councilofdeans.org.uk/wpcontent/uploads/2019/02/AUKUH-Transforming-Healthcare.pdf

Cioffi, J., Leckie, C., \& Tweedie, J. (2008). Practice development: a critique of the process to redesign an assessment. Australian Journal of Advanced Nursing, 25(2), 70-77.

Collins. (n.d.). Definition of practice development. In CollinsDictionary.com dictionary. Retrieved November 13, 2019, from https://www.collinsdictionary.com/dictionary/english/training 
Condell, S. L., \& Begley, C. (2007). Capacity building: A concept analysis of the term applied to research. International Journal of Nursing Practice, 13(5), 268-275. https://doi.org/10.1111/j.1440-172X.2007.00637.x

Considine, J., Martin, R., Smit, D., Jenkins, J., \& Winter, C. (2006). Defining the scope of practice of the emergency nurse practitioner role in a metropolitan emergency department. International Journal of Nursing Practice, 12(4), 205-213. https://doi.org/10.1111/j.1440-172X.2006.00570.x

Coombs, M., Latter, S., \& Richardson, A. (2012). Developing a clinical academic career pathway for nursing. British Journal of Nursing, 21(18), 1084-1090. https://doi.org/10.12968/bjon.2012.21.18.1084

Cregler, L. L., Clark, L. T., \& Jackson, E. B., Jr. (1994). Careers in academic medicine and clinical practice for minorities: opportunities and barriers. Journal of the Association for Academic Minority Physicians, 5(2), 68-73.

Department of Health. (2012). Developing the role of the clinical academic researcher in the Nursing, Midwifery and Allied Health Professions.

http://www.dh.gov.uk/prod_consum_dh/groups/dh_digitalassets/@dh/@en/documents/digitalass et/dh_133094.pdf

Department of Health. (2015). The NHS Constitution: The NHS belongs to us all. https://assets.publishing.service.gov.uk/government/uploads/system/uploads/attachment data/fil e/480482/NHS_Constitution_WEB.pdf

Ditzenberger, G. R., Collins, S. D., \& Banta-Wright, S. A. (1995). Combining the roles of clinical nurse specialist and neonatal nurse practitioner: The experience in one academic tertiary care setting. J Perinat Neonatal Nurs, 9(3), 45-52. https://doi.org/10.1097/00005237-199512000-00008

Edwards, N., Webber, J., Mill, J., Kahwa, E., \& Roelofs, S. (2009). Building capacity for nurse-led research. International Nursing Review, 56(1), 88-94. https://doi.org/10.1111/j.14667657.2008.00683.x

Eisenberg, E. (1987). Academic/clinical career: The best of both worlds. Journal - Connecticut State Dental Association, 61(1), 17-18.

Eley, D. S. (2018). The clinician-scientist track: An approach addressing Australia's need for a pathway to train its future clinical academic workforce. BMC Medical Education, 18(1), 227. https://doi.org/10.1186/s12909-018-1337-5

Faivre-Finn, C. (2017). Breaking the glass ceiling for women in academic clinical oncology in the UK: A personal view. Clinical Oncology, 29(1), 1-2. https://doi.org/10.1016/j.clon.2016.09.022

Fatima, R., Yaqoob, A., Qadeer, E., Hinderaker, S. G., Heldal, E., Zachariah, R., Harriesm A. D., \& Kumar, A. M. V. (2019). Building sustainable operational research capacity in Pakistan: Starting with tuberculosis and expanding to other public health problems. Global Health Action, 12(1), 1555215. https://doi.org/10.1080/16549716.2018.1555215

Finch, J. (2007). Developing the best research professionals. Qualified graduate nurses: Recommendations for preparing and supporting clinical academic nurses of the future. UKCRC. http://www.ukcrc.org/wp-content/uploads/2014/07/Nurses-report-August-07-Web.pdf

Foster, S. (2018). The need for clinical academic roles. British Journal of Nursing, 27(4), 229. https://doi.org/10.12968/bjon.2018.27.4.229

Friesen, E. L., Comino, E. J., Reath, J., Derrett, A., Johnson, M., Davies, G. P., Teng-Liaw, S., \& Kemp, L. (2014). Building research capacity in south-west Sydney through a Primary and Community 
Health Research Unit. Australian Journal of Primary Health, 20(1), 4-8. https://doi.org/10.1071/PY12081

Goldacre, M. J., Lambert, T. W., Goldacre, R., \& Hoang, U. (2011). Career plans and views of trainees in the Academic Clinical Fellowship Programme in England. Med Teach, 33(11), e637-643. https://doi.org/10.3109/0142159X.2011.610842

Gostin, L. O., \& Nass, S. (2009). Reforming the HIPAA Privacy Rule: Safeguarding privacy and promoting research. Journal of the American Medical Association, 301(13), 1373-1375. https://doi.org/10.1001/jama.2009.424

Gullick, J. G., \& West, S. H. (2016). Building research capacity and productivity among advanced practice nurses: An evaluation of the Community of Practice model. Journal of Advanced Nursing, 72(3), 605-619. https://doi.org/10.1111/jan.12850

Gunn, A. D. (1969). The nurse in general practice and the widening scope of her surgical role. Nursing Times, 65(41), 1291-1293.

Gureje, O., Seedat, S., Kola, L., Appiah-Poku, J., Othieno, C., Harris, B., Makanjuola, V., Price, L. N., Ayinde, O. O., \& Esan, O. (2019). Partnership for mental health development in Sub-Saharan Africa (PaM-D): A collaborative initiative for research and capacity building. Epidemiology and Psychiatric Sciences, 28(4), 389-396. https://doi.org/10.1017/S2045796018000707

Havens, D. S., Stone, P., \& Brewer, C. S. (2002). Nursing and health services research: building capacity and seizing opportunity. Applied Nursing Research, 15(4), 261-263. https://doi.org/10.1053/apnr.2002.37396

Health Education England (2018). Clinical academic careers framework: A framework for optimising clinical academic careers across healthcare professions. https://www.hee.nhs.uk/sites/default/files/documents/2018-02\%20CAC\%20Framework.pdf

Hicks, B. C., \& Westphal, M. (1977). Integration of clinical and academic nursing at the hospital clinical unit level. The Journal of Nursing Education, 16(4), 6-9.

Hiley, J., Jerwood, J., Price, J., Thomas, S., \& Kenkre, J. (2019). Combining a career in clinical practice and research: The benefits at junior career level. International Journal of Practice-based Learning in Health and Social Care, 7(2), 36-46. DOI 10.18552/ijpblhsc.v7i2.638

Hrynkow, S. H., Primack, A., \& Bridbord, K. (2003). Paradigms and progress in building research capacity in international environmental health. International Journal of Hygiene and Environmental Health, 206(4-5), 413-422. https://doi.org/10.1078/1438-4639-00238

Hubbard, S. M. (1982). Cancer treatment research: the role of the nurse in clinical trials of cancer therapy. Nursing Clinics of North America, 17(4), 763-783.

Huenneke, L. F., Stearns, D. M., Martinez, J. D., \& Laurila, K. (2017). Key strategies for building research capacity of university faculty members. Innovative Higher Education, 42(5-6), 421435 https://doi.org/10.1007/s10755-017-9394-y

Jamerson, P. A., Fish, A. F., \& Frandsen, G. (2011). Nursing Student Research Assistant Program: A strategy to enhance nursing research capacity building in a Magnet status pediatric hospital. Applied Nursing Research, 24(2), 110-113. https://doi.org/10.1016/j.apnr.2009.08.004

Jeffs, L., Smith, O., Beswick, S., Maoine, M., \& Ferris, E. (2013). Investing in nursing research in practice settings: A blueprint for building capacity. Nursing Leadership, 26(4), 44-59. https://doi.org/10.12927/cjnl.2013.23630 
Leao, E. R., Farah, O. G., Reis, E. A., Barros, C. G., \& Mizoi, C. S. (2013). Perfil acadêmico, crenças e autoeficácia em pesquisa de enfermeiros clínicos: implicações para o Programa de Pesquisa de Enfermagem de um Hospital na Jornada Magnet ${ }^{\circledR}$ [Academic profile, beliefs, and self-efficacy in research of clinical nurses: implications for the Nursing Research Program in a Magnet Journey hospital]. Einstein (Sao Paulo), 11(4), 507-513. https://doi.org/10.1590/S1679$\underline{45082013000400018}$

Lionis, C., Dumitra, G., Kurpas, D., Tsiligianni, I., Papadakis, S., \& Petrazzuoli, F. (on behalf of EURIPA). (2018). Building research capacity in rural health settings: Barriers, priorities and recommendations for practitioners. Australian Journal of Rural Health, 26(4). https://doi.org/10.1111/ajr.12422 doi:10.1111/ajr.12422

Liu, W., Zhang, H., Jing, M., Zhang, H., \& Liu, G., (2018). The establishment and implementation of research nurse. Chinese Nursing Management, 2018(7), 937-939.

Macpherson, C. C. (2019). Research ethics guidelines and moral obligations to developing countries: Capacity-building and benefits. Bioethics, 33(3), 399-405. https://doi.org/10.1111/bioe.12577

Masood, M., Newton, T., Kharbanda, O. P., Masood, Y., Feine, J., Gussy, M., \& Lahti, S. (2017). Building oral health research capacity in India: Identifying barriers and enablers using mixed methods. JDR Clinical \& Translational Research, 2(2), 106-108. https://doi.org/10.1177/2380084417691722

Masterson, A., \& Robb, L. (2016). Clinical academic careers: Embracing the art and science of nursing. Nursing Standard, 31(13), 40-42. https://doi.org/10.7748/ns.2016.e10553

Matus, J., Walker, A., \& Mickan, S. (2018). Research capacity building frameworks for allied health professionals - A systematic review. BMC Health Services Research, 18(1), 716. https://doi.org/10.1186/s12913-018-3518-7

McCance, T. V., Fitzsimons, D., Keeney, S., Hasson, F., \& McKenna, H. P. (2007). Capacity building in nursing and midwifery research and development: An old priority with a new perspective. Journal of Advanced Nursing, 59(1), 57-67. https://doi.org/10.1111/j.1365-2648.2007.04280.x

McConnell, D., Slevin, O. D., \& McIlfatrick, S. J. (2013). Emergency nurse practitioners' perceptions of their role and scope of practice: Is it advanced practice? International Emergency Nursing, 21(2), 76-83. https://doi.org/10.1016/j.ienj.2012.03.004

Merriam-Webster. (n.d.). Definition of research. In Merriam-Webster.com dictionary. Retrieved November 13, 2019, from https://www.merriam-webster.com/dictionary/research

Minnesota State. (2019). Career pathways. careerwise.minnstate.edu/careers/pathways.html

Mohammadi, N. K., Zaree, F., de Leeuw, E., \& Emamjomeh, M. (2011). Share of nations in 37 international public health journals: An equity and diversity perspective towards health research capacity building. Iran Journal of Public Health, 40(4), 129-137.

Mormina, M. (2019). Science, technology and innovation as social goods for development: Rethinking research capacity building from Sen's capabilities approach. Science and Engineering Ethics, 25(3), 671-692. https://doi.org/10.1007/s11948-018-0037-1

Nair, S., Tarey, S. D., Barathi, B., Mary, T. R., Mathew, L., \& Daniel, S. P. (2016). Experience in strategic networking to promote palliative care in a clinical academic setting in India. Indian Journal of Palliative Care, 22(1), 3-8. https://doi.org/10.4103/0973-1075.173953 
Nedd, N. (2006). Perceptions of empowerment and intent to stay. Nursing Economics, 24(1), 13-18, 13.

NHS England. (2019). The 14 allied health professions. https://www.england.nhs.uk/ahp/role/

Nielsen, O. L., Kongsted, A., \& Christensen, H. W. (2015). The chiropractic profession in Denmark 2010-2014: A descriptive report. Chiropractic \& Manual Therapies, 23, 27. https://doi.org/10.1186/s12998-015-0072-9

National Institute for Health Research. (2019a). NIHR strategic review of training 2017. https://www.nihr.ac.uk/documents/nihr-strategic-review-of-training-2017/21332

National Institute for Health Research. (2019b). The NIHR nursing and midwifery incubator. https://www.nihr.ac.uk/documents/the-nihr-nursing-and-midwifery-incubator/22559

Nursing \& Midwifery Council. (2018). The Code: Professional standards of practice and behaviour for nurses, midwives and nursing associates.

https://www.nmc.org.uk/globalassets/sitedocuments/nmc-publications/nmc-code.pdf

Nursing \& Midwifery Council. (2019). Standards for competence for registered midwives. https://www.nmc.org.uk/standards/standards-for-midwives/standards-of-competence-forregistered-midwives/

Page, S. (2001). Demystifying practice development. Nursing Times, 97(22), 36-37.

Pager, S., Holden, L., \& Golenko, X. (2012). Motivators, enablers, and barriers to building allied health research capacity. Journal of Multidisciplinary Healthcare, 5, 53-59. https://doi.org/10.2147/JMDH.S27638

Peloquin, S. M., \& Abreu, B. C. (1996). The academic and clinical worlds: Shall we make meaningful connections? American Journal of Occupational Therapy, 50(7), 588-591. https://doi.org/10.5014/ajot.50.7.588

Pilowsky, D. J., Rojas, G., Price, L. N., Appiah-Poku, J., Razzaque, B., Sharma, M., Schneider, M., Seedat, S., Bonini, B. B., Gureje, O., Kola, L., Lund, C., Sorsdahl, K., Araya, R., \& Menezes, P. R. (2016). Building research capacity across and within low- and middle-income countries: The collaborative hubs for international research on mental health. Academic Psychiatry, 40(4), 686691. https://doi.org/10.1007/s40596-016-0493-3

Richardson, A., Avery, M., \& Westwood, G. (2019). A cross-funder survey of enablers and barriers to progressing a research-related academic career in the non-medical health professions. https://cdn.southampton.ac.uk/assets/imported/transforms/contentblock/UsefulDownloads_Download/954F8F73B2ED47C8BE68DC29D2359507/Cross\%20Fund er\%20Survey\%20Summary\%20Document\%20April\%202019.pdf

Ryan, B. L., Thorpe, C., Zwarenstein, M., Wickett, J., Talukdar, N., Boisvert, L., \& Wetmore, S. J. (2019). Building research culture and capacity in academic family medicine departments: Insights from a simulation workshop. Canadian Family Physician, 65(1), e38-e44.

Sabey, A., Bray, I., \& Gray, S. (2019). Building capacity to use and undertake applied health research: Establishing a training programme for the health workforce in the West of England. Public Health, 167, 62-69. https://doi.org/10.1016/j.puhe.2018.11.001

Sculier, J. P. (2008). Comment faire survivre la recherche clinique académique (non commerciale)? [How can one insure the survival of clinical academic research?]. Revue Medicale de Bruxelles, 29(5), 497-499. 
Shang, S., Wu, X., Gao, Y., Jin, J., Li, Y., Cheng, S., Wen, X., Wang, A., Li, Q., Li, M., Cao, J., \& Wu, X. (2018). Investigation of nurses' scientific research competency and training demand in Chinese tertiary hospitals. Chinese Journal of Nursing, 53(3), 277-280.

Smith, M. C., \& Rattray, J. (2009). 2020-Clinical Academic Careers: Implications for critical care nursing. Nursing in Critical Care, 14(1), 2-3. https://doi.org/10.1111/j.1478-5153.2008.00315.x

Sørensen, E. E., Kusk, K. H., Athlin, A. M., Lode, K., Rustøen, T., Salmela, S., \& Hølge-Hazelton, B. (2019). The role of PhD-prepared, hospital-based nurses: An inter-Nordic study. Journal of Research in Nursing, 24(7), 470-485. https://doi.org/10.1177/1744987119877213

Squires, A. (2019). US nursing and midwifery research capacity building opportunities to achieve the United Nations sustainable development goals. Nursing Outlook, 67(6), 642648.https://doi.org/10.1016/j.outlook.2019.06.016

Squires, A., Chitashvili, T., Djibuti, M., Ridge, L., \& Chyun, D. (2017). Health research capacity building in Georgia: A case-based needs assessment. Public Health, 147, 1-7. https://doi.org/10.1016/j.puhe.2017.01.024

Strickland, K. (2017). Developing an infrastructure to support clinical academic careers. British Journal of Nursing, 26(22), 1249-1252. https://doi.org/10.12968/bjon.2017.26.22.1249

Thelen, M. H., \& Ewing, D. R. (1970). Roles, functions, and training in clinical psychology: A survey of academic clinicians. American Psychologist, 25(6), 550-554. https://doi.org/10.1037/h0029483

Tiffin, C. (2012, March 28). Beyond the bedside: The changing role of today's nurses. Huff Post. https://www.huffpost.com/entry/nursing-school_b_1384285

Tinker, L. [Newcastle Hospitals] (2019, May, 17). Make space for research campaign. [Video]. https://www.youtube.com/watch?v=6omlMJfDDdc\&app=desktop

Turner, J., Smith, J., Bryant, K., Haynes, T., Stewart, M. K., Kuo, D. Z., Harris, K., McCoy, S., Lovelady, N., Sullivan, G., \& Yeary, K. H. (2017). Community Building Community: The Distinct Benefits of Community Partners Building Other Communities' Capacity to Conduct Health Research. Prog Community Health Partnersh, 11(1), 81-86. https://doi.org/10.1353/cpr.2017.0010

Viney, K., Bissell, K., \& Hill, P. C. (2019). Building operational research capacity in Papua New Guinea and the Pacific Islands. Public Health Action, 9(Suppl. 1), S3. https://doi.org/10.5588/pha.19.0039

Walport, M. (2005). Medically- and dentally-qualified academic staff: Recommendations for training the researchers and educators of the future. Report of the academic careers sub-committee of modernising medical careers and the UK clinical research collaboration. UK Clinical Research Collaboration. http://www.ukcrc.org/wp-content/uploads/2014/03/Medically_and_Dentallyqualified_Academic_Staff_Report.pdf

Wand, T., \& White, K. (2007). Exploring the scope of the Emergency Department mental health nurse practitioner role. International Journal of Mental Health Nursing, 16(6), 403-412. https://doi.org/10.1111/j.1447-0349.2007.00495.x

World Health Organization. (2019). Nursing and midwifery: Key facts. https://www.who.int/newsroom/fact-sheets/detail/nursing-and-midwifery 
Young, S. L., Gorny, D. A., \& Ferrara, A. M. (1992). The clinical nurse specialist role in product research and development. Dimensions of Critical Care Nursing, 11(4), 202-209.

https://doi.org/10.1097/00003465-199207000-00005 